\title{
"Frequent exacerbator" is a phenotype of poor prognosis in Japanese patients with chronic obstructive pulmonary disease
}

This article was published in the following Dove Press journal:

International Journal of COPD

3 February 2016

Number of times this article has been viewed

\author{
Ryusuke Tomioka ${ }^{1,2}$ \\ Tomotaka Kawayama' \\ Masashi Suetomo ${ }^{1,2}$ \\ Takashi Kinoshita' \\ Yoshihisa Tokunaga' \\ Haruki Imaoka' \\ Kazuko Matsunaga' \\ Masaki Okamoto' \\ Tomoaki Hoshino' \\ 'Division of Respirology, Neurology, \\ and Rheumatology, Department of \\ Medicine, Kurume University School \\ of Medicine, Kurume, ${ }^{2}$ Respiratory \\ Medicine, Chikugo City Hospital, \\ Chikugo, Japan
}

Background: The prognosis of Japanese patients with COPD who suffer repeated exacerbations is unclear, although Westerners with such episodes have a poor prognosis.

Materials and methods: We conducted a 1-year prospective observational trial involving 90 Japanese patients with COPD: 58 nonexacerbators, 12 infrequent exacerbators, and 20 frequent exacerbators classified on the basis of exacerbation frequency (zero, one, and two or more exacerbations/year), respectively, during the previous year were observed prospectively for 1 year. The characteristics of frequent exacerbators, the frequency of exacerbation, and the period until the first event were then compared among the groups.

Results: A total of 78 patients completed the study. Frequent exacerbators had a significantly higher risk of frequent exacerbation in the following year than the case for nonexacerbators (odds ratio [95\% confidence interval] 2.94 [1.21-7.17], $P=0.0340$ ), but not in comparison with infrequent exacerbators (1.51 [0.49-4.63], $P>0.05)$. The mean annual frequency of exacerbations in the following year was significantly $(P=0.0020)$ higher in the frequent exacerbators (1.4 exacerbations/year) than in the nonexacerbators $(0.4)$, but not in the infrequent exacerbators $(0.9, P>0.05)$. The mean period until the first exacerbation was significantly shorter in the frequent exacerbators than in the infrequent or nonexacerbators $(P=0.0012)$. Independent risk factors for future frequent exacerbation included the presence of gastroesophageal reflux disease, more severe airflow obstruction, and use of inhaled corticosteroids.

Conclusion: Our present results indicate that Japanese COPD patients suffering frequent exacerbation have a poor prognosis. The characteristics of Japanese and Western COPD patients suffering frequent exacerbation are similar.

Keywords: COPD, hospitalization, exacerbation, Japanese

\section{Introduction}

Exacerbation is an important life-threatening event for patients with COPD, and can lead to hospitalization and death. ${ }^{1-4}$ Patients who suffer frequent and repeated exacerbations within 1 year have a poor prognosis, ${ }^{5}$ characterized by worsening of health-related quality of life (HRQoL), ${ }^{6,7}$ a rapid decline in lung function, ${ }^{8-10}$ and high mortality. ${ }^{11}$ Frequent exacerbators also carry a high risk of further exacerbation and hospitalization. ${ }^{11,12}$ However, it has been suggested that Japanese patients with COPD may have fewer exacerbations, and they also may have a higher proportion of elderly patients, those with emphysema, and those with a lower body mass index in comparison to Westerners. ${ }^{12-15}$ The prognosis of Japanese patients with COPD who suffer frequent and repeated exacerbations is unclear. We conducted a 1-year prospective observational trial in a daily-life setting involving 90 Japanese patients with COPD to investigate
Correspondence: Tomotaka Kawayama Division of Respirology, Neurology, and Rheumatology, Department of Medicine, Kurume University School of Medicine, 67 Asahi-machi, Kurume, Fukuoka 8300011 , Japan

Tel +81942317560

Fax +8I 942317703

Email kawayama_tomotaka@med. kurume-u.ac.jp 
whether previous moderate-to-severe exacerbations are associated with future exacerbations in this patient population.

\section{Materials and methods Study design}

We conducted a 1-year prospective observational trial in accordance with Good Clinical Practice (GCP) guidelines and approved by the ethics committee of Kurume University and Chikugo City Hospital (GCP 11-127, September 2012August 2014). Consecutive patients for whom medical records were available covering a period of at least 1 year since provision of informed consent were selected for the study; information on previous annual COPD-related exacerbations and hospitalizations was collected on the basis of those medical records. COPD patients were divided into three groups, based on the total number of moderate and severe exacerbations within the last year before enrollment in the study, ie, non- (previous moderate and severe exacerbations, 0/year), infrequent (one exacerbation/year), and frequent (two or more exacerbations/year) exacerbator groups, in accordance with a previous report. ${ }^{16}$ In addition, patients with previous hospitalizations were classified as having a subphenotype with severe exacerbation (severe exacerbators). The data collected for each patient included baseline data for previous moderate and severe exacerbations and hospitalizations; clinical parameters included age, sex, body mass index, smoking habits, smoking index, comorbidities, duration of COPD, 5 -grade modified Medical Research Council (mMRC) dyspnea scale score, ${ }^{17}$ total COPD Assessment Test (CAT) score, ${ }^{18,19}$ frequency scale for symptoms of gastroesophageal reflux disease (GERD) (FSSG), ${ }^{20}$ Center for Epidemiologic Studies Depression (CESD) scale score, ${ }^{21}$ medications, blood pressure and heart rate, lung function and blood parameters, and chest computed tomography. Duration of COPD was defined as the period (years) since the patient had been diagnosed by a physician as having COPD, emphysema, and/or chronic bronchitis. 22,23

After stable status for at least 4 weeks had been confirmed, each patient was required to regularly visit the hospital every 2 months, and to request emergency admission when the symptoms worsened. Regular respiratory medications were not changed during the period of the study, which was conducted in a daily-life setting. However, adherence to inhaled medications was not assessed. All of the patients had received annual influenza-virus vaccinations. None had received regular rehabilitation for COPD.

\section{Diagnosis and spirometric classification of COPD}

The diagnosis of COPD was based on age $\geq 40$ years, smoking index $>10$ pack-years, forced expiratory volume in 1 second $\left(\mathrm{FEV}_{1}\right) /$ forced vital capacity $(\mathrm{FVC})$ ratio of $<0.7$ after bronchodilator administration, and the spirometric GOLD (Global initiative for chronic Obstructive Lung Disease)stage classification, ie, stage I ( $\mathrm{FEV}_{1} \geq 80 \%$ predicted), II $\left(50 \% \leq \mathrm{FEV}_{1}<80 \%\right.$ predicted $)$, III $\left(30 \% \leq \mathrm{FEV}_{1}<50 \%\right.$ predicted), and IV ( $\mathrm{FEV}_{1}<30 \%$ predicted). ${ }^{1}$ Chest computed tomography confirmed that all patients had low-attenuation areas.

To exclude any patients with asthma, patients who had past symptoms of repeated spasmodic wheezes and medications for asthma and a classification of $\mathrm{FEV}_{1}>200 \mathrm{~mL}$ or $>12 \%$ after bronchodilation were excluded. ${ }^{24}$ Diagnosis of asthma-COPD overlap syndrome (ACOS) was made on the basis of a history of dyspnea and wheezing attacks at rest, large variations in daily symptoms, a fixed $\mathrm{FEV}_{1} / \mathrm{FVC}$ ratio of $<0.7$, marked reversibility of $\mathrm{FEV}_{1}$ after administration of bronchodilators ( $>15 \%$ and $>400 \mathrm{~mL}$ ), and a peripheral eosinophil count of $>600 / \mathrm{mm}^{3}$, in accordance with a previous report. ${ }^{25}$

\section{Assessment of mMRC scale, total CAT, FSSG scale, and CESD}

Baseline data for the mMRC scale, total CAT, FSSG scale, and CESD scale scores were obtained only once, based on a self-report completed by each patient after written informed consent had been obtained. ${ }^{17-21}$

\section{Comorbidities}

Information about comorbidities was obtained from the patients by interview, and the diagnoses were confirmed by physicians. However, patients who had moderate-to-severe comorbidities associated with poor prognosis, such as active malignancies, depression (CESD scale $>16$ points), ${ }^{21}$ liver cirrhosis, digestive ulcers, persistent arrhythmia, congestive heart disease, coronary artery disease, lung fibrosis and bronchiectasis, chronic renal failure requiring dialysis, and central nervous system disorders, including palsy and dementia, were excluded, in accordance with previous studies. ${ }^{26,27}$ Hypertension (systolic $>140 \mathrm{mmHg}$ or diastolic $>90 \mathrm{mmHg}$ blood pressure or use of medications), dyslipidemia (serum low$[\geq 14]$ or high- $[<4] \mathrm{mg} / \mathrm{L}$ density lipoprotein cholesterol, triglycerides $>15 \mathrm{mg} / \mathrm{L}$, or use of medications), diabetes (blood hemoglobin $\mathrm{A}_{1 \mathrm{c}} \geq 6.5 \%$ National Glycohemoglobin Standardization Program value or use of medications $)^{28}$ 
without triopathy (neuropathy, retinopathy, and nephropathy), and GERD (FSSG scale $>7$ points) ${ }^{20}$ were accepted as comorbidities. All data on medications for each patient were obtained from individual medication notebooks.

\section{Frequency and date of mortality, hospitalizations, and exacerbations}

Previous and prospective exacerbations documented in the medical records made by physicians were accepted as moderate and severe events. Moderate exacerbations that required a prescription for antibiotics and/or systemic corticosteroids were defined on the basis of symptom-based diagnosis, such as increased cough and sputum production, a change in sputum color, and worsening of dyspnea from a stable state and beyond normal day-to-day variations, ie, showing acute onset and necessitating a change in regular medication, in accordance with previous reports. ${ }^{1,29,30}$ COPD-related and other causes of death and hospitalization were prospectively followed for 1 year. COPD-related deaths and hospitalizations were considered severe exacerbations. Hospitalization was decided by each examining physician when hypoxemia required additional or intensive oxygen and/or assisted ventilation therapy, performance status was $\geq 3$, and unconsciousness occurred with COPD exacerbation. ${ }^{1,23,31}$ However, pneumonia was also recognized as exacerbation. Mild and unreported exacerbations were not considered to have been equal in severity to previous and prospective exacerbations. However, mild exacerbations were defined as those that improved naturally without any medication or administration of inhaled short-acting bronchodilators. Unreported exacerbations were considered to be those to which patients had been insensitive, or those that had been self-controlled in spite of worsening of respiratory symptoms. The patient's self-reported daily journal was not used in the study.

\section{Statistical analysis}

Data are expressed as mean \pm standard deviation (SD) and number (percentage) of non-, infrequent, and frequent exacerbators at baseline. Characteristics were compared using analysis of variance, Fisher's exact test, $\chi^{2}$-test for trend, and Tukey-Kramer honestly significant difference tests. Subsequent moderate and severe exacerbation events during 1 year of prospective observation were recognized as future risk indicators, and baseline parameters were chosen and modified in accordance with a previous report. ${ }^{16}$ KaplanMeier analyses and log-rank tests for subsequent moderate and severe exacerbations were performed in all three groups of patients.
For patients who were observed throughout the study period, the odds ratio ( $95 \%$ confidence interval $[\mathrm{CI}]$ ) of baseline parameters was determined to predict factors for future risk (subsequent exacerbations once or more and twice or more) using univariate and logistic multivariate regression analyses. Medians of age, body mass index, smoking index, and duration of COPD were 68 years, $21.4 \mathrm{~kg} / \mathrm{m}^{2}, 53.5$ packyears, and 4 years, respectively, and each median was used as the cutoff value for the analysis. Differences at $P<0.05$ were considered statistically significant. Statistical analysis was performed by the JMP ${ }^{\circledR}$ version 9.0 statistical software package (SAS Institute Inc, Cary, NC, USA).

\section{Results Study subjects}

Ninety of 110 patients who provided informed consent were finally analyzed; 32 (35.6\%) patients had suffered previous moderate and/or severe exacerbations during the last year. The numbers of patients with non-, infrequent, and frequent exacerbations were $58(64.4 \%), 12(13.3 \%)$, and $20(22.2 \%)$, respectively (Figure 1).

\section{Baseline characteristics}

At baseline, frequent exacerbators had a significantly lower body mass index, were less likely to be male or current smokers, had higher mMRC-scale grades and higher total CAT score, had a higher proportion of spirometric stages III and IV, GERD, and use of inhaled corticosteroid (ICS)/longacting muscarinic antagonist or ICS/long-acting $\beta_{2}$-agonist combination therapy, and lower lung-function parameters, including $\mathrm{FEV}_{1}, \mathrm{FVC}$, and $\mathrm{FEV}_{1} / \mathrm{FVC}$ ratio before and after bronchodilator use compared with nonexacerbators, but not in comparison with infrequent exacerbators (Table 1). Frequent and infrequent exacerbators had significantly higher mMRC-scale grades and total CAT scores compared with nonexacerbators (Table 1). There was no change in the frequency of previous annual hospitalizations per patient between those with frequent and infrequent exacerbations (Table 1).

\section{Stability of the frequent and severe exacerbation phenotype in patients who completed the study}

During the 1-year prospective observation period, one frequent exacerbator, one infrequent exacerbator, and two nonexacerbators died, with causes of death respiratory failure with COPD exacerbation, cerebrovascular attack, and malignancies (small-cell lung cancer and colon cancer), 


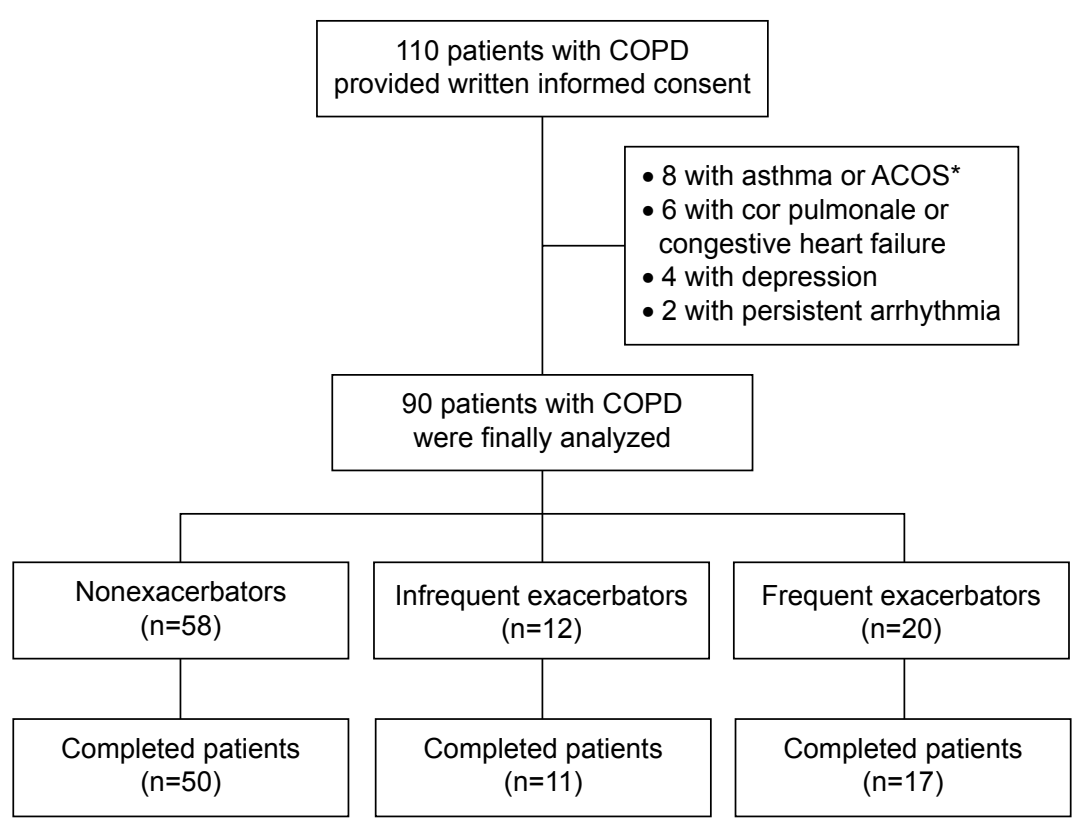

Figure I Study design.

Notes: *Diagnosis of asthma-COPD overlap syndrome (ACOS) was made in accordance with history of dyspnea and wheezing attacks at rest, and large variations of daily symptoms and $\mathrm{FEV}$, after bronchodilator administration (reversibility $>15 \%$ and $>400 \mathrm{~mL}$ ). A total of II 0 patients provided informed consent. Eight patients with asthma or ACOS, six with cor pulmonale or congestive heart failure, four with depression, and two with persistent arrhythmia were excluded. As a result, 90 patients with COPD were finally analyzed.

Abbreviation: $\mathrm{FEV}_{1}$, forced expiratory volume in I second.

respectively, whereas one frequent exacerbator and six nonexacerbators dropped out for private reasons. As a result, 78 patients ( 17 frequent, eleven infrequent, and 50 nonexacerbators) completed the study (Figure 1).

Figure 2 also shows that among the frequent exacerbators, the number of patients who subsequently suffered severe exacerbations (requiring one or more hospitalizations) was two (11.8\%), and frequent (two or more exacerbations/year), infrequent (one exacerbation/year), and no moderate or severe exacerbations were seven (42.1\%), six (35.3\%), and four (23.5\%), respectively, whereas seven (63.6\%) of eleven infrequent and 37 (74.0\%) of 50 nonexacerbators experienced no further exacerbation. The proportions of frequent exacerbators who subsequently experienced frequent and infrequent exacerbations were significantly higher than those of nonexacerbators (odds ratio [95\% CI] 2.94 [1.21-7.17], $P=0.0340$; 2.94 [1.72-5.03], $P=0.0004$, respectively), but not in comparison with infrequent exacerbators (1.51 [0.49-4.63], $P>0.05 ; 2.01[0.92-4.80], P=0.053$, respectively).

Among five $(5.6 \%)$ of the severe exacerbators, two $(40.0 \%)$ had subsequently suffered severe exacerbations. The number of patients who had subsequent frequent, infrequent, and no moderate or severe exacerbations was two (40\%), 0 , and three (60\%), respectively (Figure 2). In subanalysis, there was no difference in the proportion of patients who had subsequently suffered severe exacerbations between the frequent and severe exacerbator groups $(P>0.05)$. In addition, one severe exacerbator died due to COPD-related respiratory failure during the 1-year prospective observation period.

The numbers of patients who reported pneumonia $(\mathrm{n}=78)$ and those who regularly used ICS ( $\mathrm{n}=15)$ were seven (9\%) and three $(20 \%)$, respectively. Patients who regularly used ICS had higher but not significant contraction of pneumonia than those who did not use ICS $(P>0.05)$.

\section{Comparison of annual exacerbation and hospitalization among non-, infrequent, and frequent exacerbators}

Figure $3 \mathrm{~A}$ shows that the mean annual frequencies $( \pm \mathrm{SD}$, exacerbations/year) of future total $(1.4 \pm 1.2, P=0.0020)$ and moderate $(1.3 \pm 1.1, P=0.0057)$ exacerbations in frequent exacerbators were significantly higher than those in nonexacerbators ( $0.4 \pm 0.8$ and $0.4 \pm 0.7$, respectively), but not in infrequent exacerbators $(0.9 \pm 1.4$ and $0.8 \pm 1.4$, respectively).

Figure 3B shows the Kaplan-Meier analysis of the period until the first moderate and severe exacerbations. The median (mean \pm SD) periods (days) until the first moderate and severe exacerbations for frequent, infrequent, and nonexacerbators

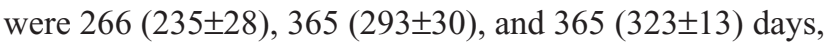
respectively (log-rank test, $P=0.0012$ ).

There was no significant difference in the annual frequencies of severe exacerbation (hospitalization) among non- (0.0 \pm 0.3$)$, infrequent $(0.1 \pm 0.39)$, and frequent $(0.1 \pm 0.3)$ exacerbators $(P>0.05)$. The median (mean $\pm \mathrm{SD}$ ) periods 
Table I Characteristics of nonexacerbators and infrequent and frequent exacerbators

\begin{tabular}{|c|c|c|c|}
\hline Characteristics & $\begin{array}{l}\text { Non } \\
\text { exacerbators }(n=58)\end{array}$ & $\begin{array}{l}\text { Infrequent } \\
\text { exacerbators }(n=12)\end{array}$ & $\begin{array}{l}\text { Frequent } \\
\text { exacerbators }(n=20)\end{array}$ \\
\hline Age, years & $66.2 \pm 6.5$ & $69.6 \pm 4.6$ & $68.0 \pm 6.4$ \\
\hline Male sex, n (\%) & $53(91.4)$ & II (9I.7) & $14(70.0)^{*}$ \\
\hline Body mass index, $\mathrm{kg} / \mathrm{m}^{2}$ & $22.7 \pm 3.1$ & $21.4 \pm 3.0$ & $18.8 \pm 3.2 * * *, \#$ \\
\hline Current smokers, n (\%) & $26(44.8)$ & $3(25.0)$ & $3(15.0)^{*}$ \\
\hline Smoking index, pack-years & $59.2 \pm 27.2$ & $62.1 \pm 23.6$ & $60.9 \pm 26.8$ \\
\hline $\begin{array}{l}\text { Frequency of previous hospitalizations within the last } \\
\text { year, times/patient (range) }\end{array}$ & 0 & $1.67 \pm 0.39 *(0-1)$ & $1.50 \pm 0.37 *(0-1)$ \\
\hline mMRC dyspnea scale, grades & $0.60 \pm 0.98$ & $1.50 \pm 1.00 *$ & $1.65 \pm 1.35 * *$ \\
\hline Total CAT score, points & $8.29 \pm 6.12$ & $|5.8 \pm 5.6| * *$ & $21.2 \pm 10.8 * * *, \#$ \\
\hline Spirometric stage I/II/III/IV, n (\% of stage III and IV) & $18 / 26 / 12 / 2(24.1)$ & I/7/2/2 (33.3) & $0 / 11 / 4 / 5^{\mathrm{a}}(45.0)$ \\
\hline Hypertension, n (\%) & $19(32.8)$ & $2(16.7)$ & $6(30.0)$ \\
\hline Diabetes, n (\%) & $23(39.7)$ & $2(16.7)$ & $6(30.0)$ \\
\hline Dyslipidemia, n (\%) & $31(53.5)$ & $6(50.0)$ & $10(50.0)$ \\
\hline Gastroesophageal reflux disease, n (\%) & $3(5.2)$ & $3(25.0)$ & $4(20.0)^{\mathrm{a}}$ \\
\hline Duration of COPD, years & $4.79 \pm 4.01$ & $7.00 \pm 3.64$ & $5.90 \pm 3.89$ \\
\hline Pneumococcal vaccination within 5 years, n (\%) & $9(15.5)$ & I (8.3) & $7(35.0)$ \\
\hline Required long-term oxygen therapy, n (\%) & $2(3.5)$ & 0 & $3(15.0)$ \\
\hline Required home ventilation support, $\mathrm{n}(\%)$ & $\mathrm{I}(\mathrm{l} .7)$ & 0 & $\mathrm{I}(5.0)$ \\
\hline No respiratory medication, $\mathrm{n}(\%)$ & $18(31.0)$ & $2(16.7)$ & $2(10.0)$ \\
\hline ICS-LABA-LAMA triple combo, n (\%) & $7(12.1)$ & I (8.3) & $4(20.0)$ \\
\hline ICS-LAMA or ICS-LABA double combo, n (\%) & I (I.7) & 0 & $3(15.0)^{\mathrm{a}}$ \\
\hline LABA-LAMA double combo, n (\%) & $4(6.9)$ & $3(8.3)$ & $\mathrm{I}(10.0)$ \\
\hline LAMA or LABA alone, $\mathrm{n}(\%)$ & $28(48.3)$ & $8(66.7)$ & $9(45.0)$ \\
\hline Regimen included ICS, n (\%) & $8(13.8)$ & I (8.33) & $7(35.0)$ \\
\hline Regimen included SRT, n (\%) & $\mathrm{I}(\mathrm{l} .7)$ & I (8.3) & $2(10.0)$ \\
\hline Regimen included mucolytic agents, $n(\%)$ & 0 & I $(8.3)^{*}$ & 0 \\
\hline \multicolumn{4}{|l|}{ Prebronchodilator } \\
\hline FVC, L & $3.70 \pm 0.79$ & $3.28 \pm 0.7 \mathrm{I}$ & $2.82 \pm 0.8 \mathrm{I} * *$ \\
\hline FVC predicted, \% & $105 \pm 18.0$ & $93.4 \pm 15.6$ & $88.6 \pm 18.2 * *$ \\
\hline $\mathrm{FEV}_{1}, \mathrm{~L}$ & $1.86 \pm 0.64$ & $1.44 \pm 0.66$ & $1.20 \pm 0.59 * *$ \\
\hline FEV , predicted, \% & $65.4 \pm 21.9$ & $50.8 \pm 19.9$ & $47.5 \pm 21.4 * *$ \\
\hline $\mathrm{FEV}_{\mathrm{I}} / \mathrm{FVC}$ ratio, \% & $50.0 \pm 13.5$ & $42.6 \pm 13.1$ & $42.0 \pm 14.5$ \\
\hline \multicolumn{4}{|l|}{ Postbronchodilator } \\
\hline FVC, L & $3.74 \pm 0.77$ & $3.38 \pm 0.74$ & $2.88 \pm 0.84 * *$ \\
\hline FVC predicted, \% & $106 \pm 18.0$ & $95.4 \pm 15.6$ & $88.6 \pm 18.2^{* *}$ \\
\hline $\mathrm{FEV}_{1}, \mathrm{~L}$ & $1.92 \pm 0.65$ & $1.5 I \pm 0.68$ & $1.28 \pm 0.63 * *$ \\
\hline $\mathrm{FEV}$, predicted, \% & $67.3 \pm 21.8$ & $53.5 \pm 20.2$ & $50.4 \pm 22.6 * *$ \\
\hline $\mathrm{FEV}_{1} / \mathrm{FVC}$ ratio, \% & $51.2 \pm 13.9$ & $43.9 \pm 13.7$ & $43.3 \pm 14.2$ \\
\hline Reversibility of FEV, postbronchodilation, \% & $3.65 \pm 7.96$ & $5.64 \pm 4.24$ & $6.85 \pm 12.8$ \\
\hline
\end{tabular}

Notes: a $P<0.05$ vs nonexacerbators by $\chi^{2}$-test for trend. ${ }^{*} P<0.05$, ${ }^{*} * P<0.01$, and ${ }^{* * *} P<0.0001$ vs nonexacerbators; ${ }^{\# P<0.05}$ vs infrequent exacerbators. Data expressed as mean \pm standard deviation and number (percentage) of patients.

Abbreviations: CAT, COPD Assessment Test; FEV , forced expiratory volume in I second; FVC, forced vital capacity; ICS, inhaled corticosteroids; LABA, long-acting $\beta_{2}$-agonist; LAMA, long-acting muscarinic antagonist; mMRC, modified Medical Research Council; SRT, slow-release theophylline.

until the first severe exacerbation were $365(363 \pm 2), 365$ (365 \pm 0$)$, and 365 (360 \pm 5$)$ days, respectively ( $P>0.05$; data not shown).

\section{Baseline characteristics of patients suffering further exacerbations (one or more/year) and frequent exacerbations (two or more/year)}

Univariate analysis revealed that a low $\mathrm{FEV}_{1}(<50 \%)$ had the highest odds ratio for risk of future exacerbation (one or more exacerbations/year), followed in order by regular use of ICS, two or more previous exacerbations in the last year, presence of GERD, pneumococcal vaccination, one or more previous exacerbations in the last year, low body mass index $\left(\leq 21.4 \mathrm{~kg} / \mathrm{m}^{2}\right)$, a high total CAT score ( $\geq 10$ points), a high mMRC scale grade $(\geq 2)$ and older age ( $\geq 68$ years), whereas in patients who suffered two or more exacerbations, the highest odds ratio was observed due to the presence of GERD, followed in order by regular use of ICS, low FEV predicted, pneumococcal vaccination, older age, a high 


\section{Previous risks}

\section{Future risks}

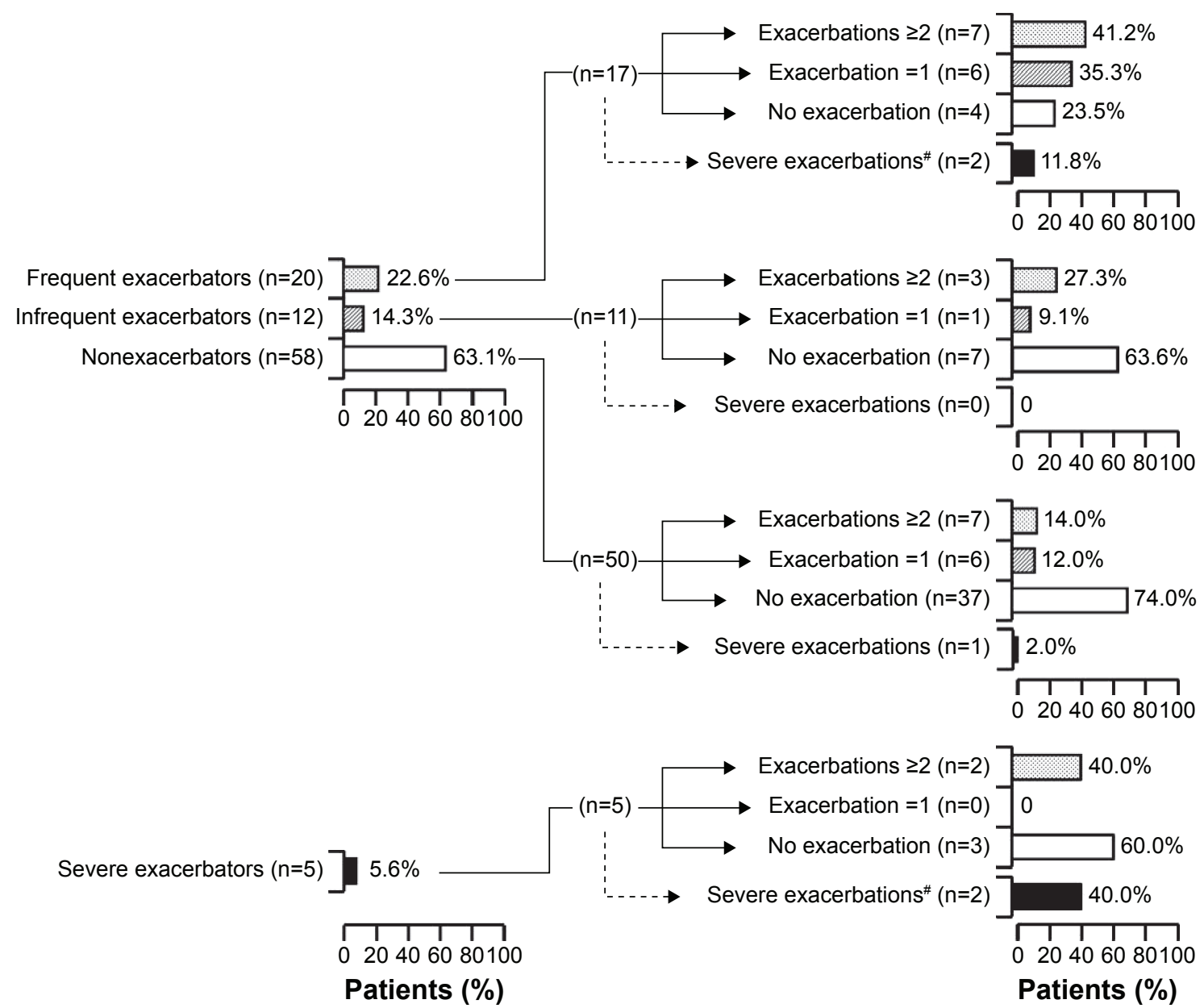

Figure 2 Stability of the phenotypes of frequent and infrequent exacerbators, nonexacerbators, and severe exacerbators.

Notes: \#Three patients who had subsequent severe exacerbations in 78 completed patients, and two of 17 , zero of eleven, and one of 50 patients were frequent, infrequent, and nonexacerbators, respectively (dotted lines). Two frequent exacerbators required hospitalization due to COPD exacerbations, and one died due to respiratory failure. In analysis of subphenotypes with severe exacerbators, two of five patients had subsequent severe exacerbations (dotted line). The bars at the previous (left) and future (right) risk show the proportions of patients who suffered severe, frequent, and infrequent exacerbations, and nonexacerbators retrospectively and prospectively, respectively, based on the number of previous moderate and severe exacerbations for I year.
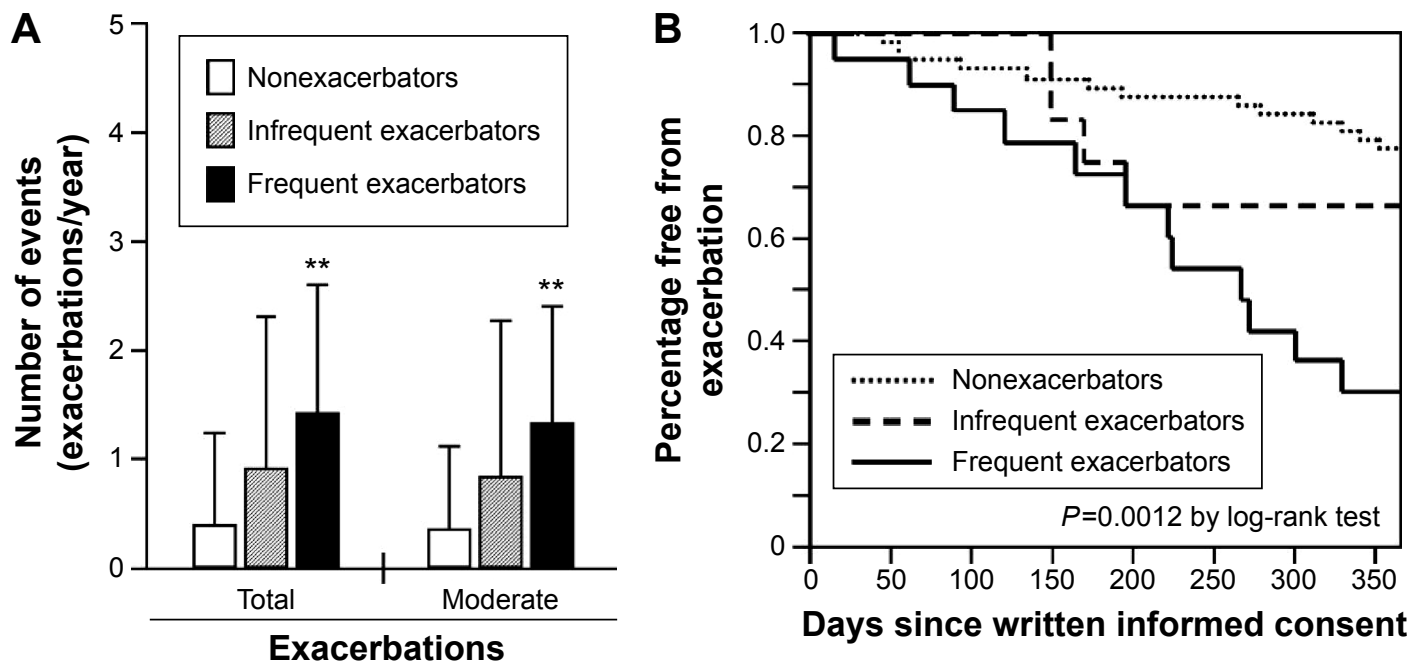

Figure 3 Comparison of annual exacerbation and hospitalization among nonexacerbators and infrequent and frequent exacerbators.

Notes: ${ }^{*} * \mathrm{P}<0.0 \mathrm{I}$ vs nonexacerbators. (A) All data expressed as the frequency (exacerbations/year) of moderate or severe (deaths and hospitalizations) exacerbation (error bars = standard deviation). (B) Kaplan-Meier curves of periods until first moderate and severe exacerbations. 
Table 2 Baseline characteristics of patients with future exacerbation (once or more) and frequent exacerbation (twice or more) by univariate analysis

\begin{tabular}{|c|c|c|c|c|}
\hline \multirow[t]{2}{*}{ Parameters } & \multicolumn{2}{|c|}{ Once or more } & \multicolumn{2}{|c|}{ Twice or more } \\
\hline & n/total & OR $(95 \% \mathrm{CI})$ & n/total & OR $(95 \% \mathrm{Cl})$ \\
\hline Age $\geq 68$ years & $20 / 40$ & $2.80(1.08-7.25)^{*}$ & $14 / 40$ & $6.28(1.63-24.1)^{* *}$ \\
\hline Male sex & $27 / 69$ & $1.29(0.30-5.58)$ & $15 / 69$ & $0.97(0.18-5.18)$ \\
\hline Body mass index $\leq 21.4 \mathrm{~kg} / \mathrm{m}^{2}$ & $21 / 39$ & $3.89(1.47-10.3)^{* *}$ & $11 / 39$ & $2.16(0.7 I-6.59)$ \\
\hline Current smokers & $7 / 26$ & $0.46(0.17-1.29)$ & $3 / 26$ & $0.35(0.09-1.37)$ \\
\hline Smoking index $\geq 53.5$ pack-years & $17 / 39$ & $1.55(0.62-3.87)$ & $10 / 39$ & $1.57(0.53-4.68)$ \\
\hline Previous exacerbations once or more in the last year & $17 / 28$ & $4.40(1.64-11.8)^{* *}$ & $10 / 28$ & $3.41(1.12-10.4)^{*}$ \\
\hline Previous exacerbations twice or more in the last year & $13 / 17$ & $8.4 \mathrm{I}(2.40-29.3)^{* *}$ & $7 / 17$ & $3.57(1.10-9.24)^{*}$ \\
\hline Previous hospitalizations in the last year & $2 / 5$ & $1.07(0.17-6.82)$ & $2 / 5$ & $2.58(0.40-16.8)$ \\
\hline $\mathrm{mMRC}$ scale $\geq 2$ grades & $|3 / 2|$ & $3.82(1.34-10.9)^{*}$ & $9 / 24$ & $4.59(1.47-14.4)^{*}$ \\
\hline Total CAT score $\geq 10$ points & $22 / 42$ & $3.85(1.43-10.4)^{* *}$ & $13 / 42$ & $3.59(1.05-12.2)$ \\
\hline Hypertension, yes & $9 / 23$ & $1.04(0.38-2.83)$ & $6 / 23$ & $1.4 \mathrm{I}(0.45-4.42)$ \\
\hline Diabetes, yes & $12 / 27$ & $1.46(0.57-3.80)$ & $9 / 30$ & $2.14(0.72-6.37)$ \\
\hline Dyslipidemia, yes & $14 / 38$ & $0.88(0.35-2.18)$ & $7 / 38$ & $0.68(0.23-2.01)$ \\
\hline Gastroesophageal reflux disease, yes & $7 / 9$ & $7.00(1.35-36.4)^{*}$ & $6 / 10$ & $10.5(2.29-48.6)^{* *}$ \\
\hline Duration of COPD $\geq 4$ years & $|9 / 4|$ & $2.04(0.80-5.20)$ & $|3 / 4|$ & $3.83(1.12-13.1)^{*}$ \\
\hline Pneumococcal vaccination, yes & $11 / 15$ & $6.34(1.80-22.6)^{* *}$ & $8 / 15$ & $6.86(2.00-23.6)^{*}$ \\
\hline Regular users of ICS, yes & $12 / 15$ & $10.0(2.52-39.7)^{* *}$ & $9 / 15$ & $10.3(2.89-37.8)^{* * *}$ \\
\hline FEV , predicted $<50 \%$ & $18 / 24$ & $10.5(3.4 \mathrm{I}-32.3)^{* * * *}$ & $12 / 24$ & $9.80(2.89-33.2)^{* * *}$ \\
\hline
\end{tabular}

Notes: $* P<0.05 ; * * P<0.01 ; * * * P<0.0001$.

Abbreviations: CAT, COPD Assessment Test; $\mathrm{Cl}$, confidence interval; FEV , forced expiratory volume in I second; ICSs, inhaled corticosteroids; mMRC, modified Medical Research Council; OR, odds ratio.

mMRC-scale grade, long duration of COPD ( $\geq 4$ years), and two or more and one or more previous exacerbations in the last year (Table 2). However, 13 (86.7\%) of 15 patients who had received ICS had also received pneumococcal vaccination.

The independent risk factors for both one or more and two or more future exacerbations were low $\mathrm{FEV}_{1}$ predicted, presence of GERD, and regular use of ICS, whereas a low body mass index was an independent risk factor for one or more but not for two or more future exacerbations (Table 3).

\section{Discussion}

The frequent-exacerbator phenotype is important to consider in the management of COPD patients, who require future exacerbation-related hospitalization associated with

Table 3 Baseline characteristics of patients with future exacerbation (once or more) and frequent exacerbation (twice or more) by multivariate analysis

\begin{tabular}{|c|c|c|c|c|}
\hline \multirow[t]{2}{*}{ Parameters } & \multicolumn{2}{|l|}{ Once or more } & \multicolumn{2}{|l|}{ Twice or more } \\
\hline & OR $(95 \% \mathrm{Cl})$ & $P$-value & OR (95\% CI) & $P$-value \\
\hline Age $\geq 68$ years & $2.38(0.51-11.9)$ & 0.3 & $2.29(0.35-16.5)$ & 0.4 \\
\hline $\mathrm{BMI} \leq 2 \mathrm{I} .4 \mathrm{~kg} / \mathrm{m}^{2}$ & $5.66(1.24-32.4)$ & 0.0245 & - & - \\
\hline Previous exacerbations twice or more in last year* & $3.73(0.74-20.8)$ & 0.1 & $1.52(0.24-8.94)$ & 0.6 \\
\hline $\mathrm{mMRC}$ scale $\geq 2$ grades & $0.31(0.04-1.95)$ & 0.2 & $0.83(0.10-5.96)$ & 0.8 \\
\hline Total CAT score $\geq 10$ points & $1.35(0.31-5.90)$ & 0.7 & $1.00(0.17-5.76)$ & 1.0 \\
\hline GERD, yes & $10.2(1.06-130)$ & 0.0440 & 14.5 ( $1.68-197)$ & 0.0139 \\
\hline Duration of $C O P D \geq 4$ years & - & - & $2.19(0.43-12.8)$ & 0.3 \\
\hline Regular users of ICS, yes** & $8.12(1.31-68.4)$ & 0.0236 & $6.92(1.14-48.9)$ & 0.0356 \\
\hline FEV, predicted $<50 \%$ & $16.6(3.37-115)$ & 0.0003 & $8.69(1.68-57.1)$ & 0.0095 \\
\hline
\end{tabular}

Notes: $* O R(95 \% \mathrm{Cl})$ of previous exacerbations once or more in the last year to future exacerbation once or more and twice or more $3.37(0.64-18.5, P>0.05)$ and 1.40 (0.42-28.0, $P>0.05)$, respectively, by multivariate analysis adjusted for age, BMI, mMRC scale, total CAT score, presence of GERD, duration of COPD, and regular use of ICS. **OR $(95 \% \mathrm{Cl})$ of inoculation of pneumococcal vaccination to future exacerbation once or more and twice or more I.56 $(0.22-10.1, P>0.05)$ and $2.23(0.4 \mathrm{I}-\mathrm{II} .8$, $P>0.05$ ), respectively, by multivariate analysis adjusted for age, BMI, previous exacerbations twice or more, mMRC scale, total CAT score, presence of GERD, and duration of COPD.

Abbreviations: BMI, body mass index; CAT, COPD Assessment Test; $\mathrm{Cl}$, confidence interval; $\mathrm{FEV}$, forced expiratory volume in I second; GERD, gastroesophageal reflux disease; ICS, inhaled corticosteroids; mMRC, modified Medical Research Council; OR, odds ratio. 
high mortality. ${ }^{16}$ A previous Western study suggested that frequent exacerbators tend to have had exacerbations during the previous year, a lower FEV ${ }_{1}$, more severe HRQoL, a history of GERD, and a higher peripheral white bloodcell count in comparison with infrequent exacerbators and nonexacerbators. ${ }^{12}$ Another Western study demonstrated that the characteristics of frequent exacerbators include a more severe mMRC-scale grade, lower $\mathrm{FEV}_{1}$ predicted, comorbid cardiovascular disease, depression or osteoporosis, and female sex as independent risk factors. ${ }^{32,33}$ We conducted the present study to observe moderate and severe exacerbations 1 year before and after baseline to investigate the characteristics of Japanese COPD patients who were frequent exacerbators. Based on exacerbations during the previous year, we found that frequent exacerbators were more likely to be female, have a lower body mass index, have a significantly lower $\mathrm{FEV}_{1}$ predicted, have a higher mMRC-scale grade (lower exercise tolerance), and have a lower total CAT score (lower HRQoL). We also found that the characteristics of frequent exacerbators were similar between Japanese and Westerners, except for body mass index, as reported previously. ${ }^{12,16,32}$ Interestingly, univariate analysis did not show that previous frequent exacerbators would become future frequent exacerbators (Table 2). Indeed, 60\% of previous frequent exacerbators did not suffer subsequent exacerbations, whereas conversely $14 \%$ of patients who had not previously suffered exacerbations subsequently did so (Figure 2). Investigation of factors predicting the change in frequency of exacerbations is critically important, as they are still unclear. ${ }^{34}$

A total of $78(86.7 \%)$ of our 90 patients completed the 1 -year prospective study period. Among five severe exacerbators, one (20\%) died, two (40\%) again developed severe exacerbation, and two (40\%) became frequent exacerbators in the following year. Therefore, severe exacerbators appear to have a poor prognosis. However, our study-sample size was small and the observational period short. Further analysis will therefore be needed to verify this issue. Frequent exacerbators had a significantly higher frequency of future exacerbations and a shorter period until the next exacerbation than nonexacerbators, and also had a significantly poorer prognosis than the latter, thus confirming the findings of a previous study. ${ }^{12}$

Previous studies have demonstrated that over half of COPD patients have unreported exacerbations. Such unreported exacerbations are thought to be an important compo-

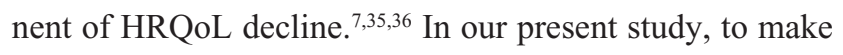
the conditions for previous and future exacerbations uniform, daily journals for symptoms were not accepted. Therefore, mild and unreported exacerbations were unclear. Previous studies have demonstrated that the frequency of annual moderate or severe exacerbations per patient in Japanese individuals may be lower than that in the USA and Europe. ${ }^{13,14,35-37}$ In our study, the mean ( \pm SD [range]) of previous annual total and severe exacerbations were $0.84 \pm 1.48(0-6)$ and $0.06 \pm 0.23(0-1)$ exacerbations/year, respectively for all patients (data not shown), whereas those of future total and severe exacerbations were $0.71 \pm 1.08(0-4)$ and $0.06 \pm 0.28$ (0-2) exacerbations/year, respectively. Our data for the frequency of exacerbations seem to indicate a slightly lower incidence in Japanese than in Westerners. ${ }^{12-15,31,32,38}$ Previous Japanese reports on the frequency of exacerbations have been scarce. ${ }^{13,14}$ Japanese COPD patients may be slightly older and thinner on average than Westerners. ${ }^{12-15,31,32,38}$ Although the discrepancy between Japanese and Westerners is still unclear, the difference in the frequency of exacerbations may be associated with different populations of phenotypes with emphysema, locality, and understanding of both the physician and the patient about diseases and exacerbations, such as convenient use of ICS, and in definition of exacerbation.

Patients with COPD have a wide variety of numerous comorbidities, which are strongly associated with mortality and exacerbation. ${ }^{1,12,26}$ We assessed baseline comorbidities based on interviews with patients and the physicians' diagnosis, and partly through examinations or questionnaires. Several comorbidities, such as depression ${ }^{21,39}$ assessed by the CESD questionnaire, $\operatorname{ACOS}^{27,40}$ based on previous criteria, and congestive status with heart failure and cor pulmonale based on history or medical signs, ${ }^{41}$ were carefully excluded. GERD, although not moderate to severe, was a common major comorbidity, and the proportion of frequent exacerbators with GERD was significantly higher than that of nonexacerbators. GERD was an independent, and the highest, risk factor for future frequent exacerbations, although all patients with GERD were receiving proton-pump inhibitors. Our results confirmed previous reports. ${ }^{12,42}$

A low $\mathrm{FEV}_{1}$ predicted was an independent risk factor for future exacerbations. The guidelines ${ }^{1,43}$ recommend long-term treatment with ICS and pneumococcal vaccination for patients with severe and very severe COPD, and frequent exacerbations may not be adequately controlled by long-acting bronchodilators. In our study, most patients who regularly used ICS also received pneumococcal vaccination. Regular use of ICS, but not pneumococcal vaccination, was an independent risk factor for future frequent exacerbations. Sixteen $(17.8 \%)$ of our patients used ICS, although none had received ICS without long-acting bronchodilators at baseline. Users of ICS included four nonexacerbators with 
GOLD stage II, seven patients with frequent exacerbations, and the remaining five had severe or very severe disease. The risk of ICS for respiratory infection including pneumonia is a concern. ${ }^{44-46}$ Among four nonexacerbators with GOLD stage II and users of ICS during the prospective observation period, two patients had frequent exacerbations and one had infrequent exacerbations. This risk must be weighed against the benefits when prescribing ICS to patients with COPD.

Our study had some limitations. First, the study population was small and the observation period rather short for analyzing severe exacerbations and mortality. Balcells et al demonstrated that female sex was the highest risk factor for exacerbation, ${ }^{33}$ although in the present study there was no difference in the frequency of exacerbations between males and females. This discrepancy may have been attributable to sample size. Second, our protocol was not double-blinded. Both physicians and patients were aware of the severity and frequency of previous exacerbations at baseline. Third, dealing with comorbidity was difficult. We carefully removed severe comorbidities, such as cardiovascular disease and depression, in accordance with previous reports. ${ }^{26,27}$ However, patients with asthma and ACOS may have been included, because we did not investigate airway responsiveness and inflammation or serum total immunoglobulin (Ig) E levels, although we carefully excluded patients with asthma based on symptoms and spirometry. However, no patients had received medications for osteoporosis and low peripheral lymphocyte counts, although latent osteoporosis and HIV infections were not tested for. Fourth, the contents of medicines could not be ethically unified in a clinical setting in Japan, and in our study adherence to pharmacological medicines and compliance with inhalation techniques were not assessed or included. The effects of respiratory medications, including inhaled medicines, on previous and future exacerbations were investigated. Further trials will be necessary to clarify the limitations of our approach.

\section{Conclusion}

Our results indicate that Japanese COPD patients with frequent exacerbations have a poor prognosis. The characteristics of frequent exacerbators among Japanese and Western patients are similar. The presence of GERD, regular use of ICS, and low FEV 1 may be associated with frequent exacerbations.

\section{Acknowledgments}

The authors are grateful to Masaharu Kinoshita, $\mathrm{MD}, \mathrm{PhD}$, Yanagawa Nagata Hospital, and Tatsuya Mukaino, MD, Social Insurance Tagawa Hospital, for collection of data on the study subjects. The authors are also grateful to Prof Tatsuyuki Kakuma, Biostatistics Center, Kurume University School of Medicine, for support with statistical analysis. The authors are also grateful to Dr Howard A Young, National Cancer Institute - Frederick, for reading our manuscript and providing English-language editing.

\section{Author contributions}

All authors contributed toward data analysis, drafting and critically revising the paper and agree to be accountable for all aspects of the work.

\section{Disclosure}

Tomotaka Kawayama received grants from AstraZeneca, Japan; MSD KK (Merck), Japan; and Novartis Pharmaceuticals, Japan; and lecture fees from Novartis Pharmaceuticals, Japan; GSK, Japan; Boehringer Ingelheim, Japan; and AstraZeneca, Japan. Tomoaki Hoshino received a grant from GSK, Japan; Novartis Pharmaceuticals, Japan and Chugai Pharmaceutical Co Ltd., Japan. The other authors report no conflicts of interest in this work.

\section{References}

1. GOLD (Global initiative for chronic Obstructive Lung Disease). Global Strategy for Diagnosis, Management, and Prevention of COPD. Bethesda (MD): GOLD; 2015.

2. Singanayagam A, Schembri S, Chalmers JD. Predictors of mortality in hospitalized adults with acute exacerbation of chronic obstructive pulmonary disease. Ann Am Thorac Soc. 2013;10(2):81-89.

3. Bustamante-Fermosel A, De Miguel-Yanes JM, Duffort-Falcó M, Muñoz J. Mortality-related factors after hospitalization for acute exacerbation of chronic obstructive pulmonary disease: the burden of clinical features. Am J Emerg Med. 2007;25(5):515-522.

4. Groenewegen KH, Schols AM, Wouters EF. Mortality and mortalityrelated factors after hospitalization for acute exacerbation of COPD. Chest. 2003;124(2):459-467.

5. Seemungal TA, Hurst JR, Wedzicha JA. Exacerbation rate, health status and mortality in COPD - a review of potential interventions. Int J Chron Obstruct Pulmon Dis. 2009;4:203-223.

6. Spencer S, Calverley PM, Burge PS, Jones PW. Impact of preventing exacerbations on deterioration of health status in COPD. Eur Respir J. 2004;23(5):698-702.

7. Seemungal TA, Donaldson GC, Paul EA, Bestall JC, Jeffries DJ, Wedzicha JA. Effect of exacerbation on quality of life in patients with chronic obstructive pulmonary disease. Am J Respir Crit Care Med. 1998; 157(5 Pt 1):1418-1422.

8. Celli BR, Thomas NE, Anderson JA, et al. Effect of pharmacotherapy on rate of decline of lung function in chronic obstructive pulmonary disease: results from the TORCH study. Am J Respir Crit Care Med. 2008;178(4):332-338.

9. Makris D, Moschandreas J, Damianaki A, et al. Exacerbations and lung function decline in COPD: new insights in current and ex-smokers. Respir Med. 2007;101(6):1305-1312.

10. Donaldson GC, Seemungal TA, Bhowmik A, Wedzicha JA. Relationship between exacerbation frequency and lung function decline in chronic obstructive pulmonary disease. Thorax. 2002;57(10):847-852.

11. Soler-Cataluña JJ, Martínez-García MA, Román Sánchez P, Salcedo E, Navarro M, Ochando R. Severe acute exacerbations and mortality in patients with chronic obstructive pulmonary disease. Thorax. 2005; 60(11):925-931. 
12. Hurst JR, Vestbo J, Anzueto A, et al. Susceptibility to exacerbation in chronic obstructive pulmonary disease. $N$ Engl J Med. 2010;363(12): 1128-1138.

13. Suzuki M, Makita H, Ito YM, Nagai K, Konno S, Nishimura M. Clinical features and determinants of COPD exacerbation in the Hokkaido COPD cohort study. Eur Respir J. 2014;43(5):1289-1297.

14. Fukuchi Y, Fernandez L, Kuo HP, et al. Efficacy of tiotropium in COPD patients from Asia: a subgroup analysis from the UPLIFT trial. Respirology. 2011;16(5):825-835.

15. Tatsumi K, Kasahara Y, Kurosu K, Tanabe N, Takiguchi Y, Kuriyama T. Clinical phenotypes of COPD: results of a Japanese epidemiological survey. Respirology. 2004;9(3):331-336.

16. Beeh KM, Glaab T, Stowasser S, et al. Characterisation of exacerbation risk and exacerbator phenotypes in the POET-COPD trial. Respir Res. 2013;14:116.

17. Bestall JC, Paul EA, Garrod R, Garnham R, Jones PW, Wedzicha JA. Usefulness of the Medical Research Council (MRC) dyspnoea scale as a measure of disability in patients with chronic obstructive pulmonary disease. Thorax. 1999;54(7):581-586.

18. Tsuda T, Suematsu R, Kamohara K, et al. Development of the Japanese version of the COPD Assessment Test. Respir Investig. 2012;50(2):34-39.

19. Jones PW, Harding G, Berry P, Wiklund I, Chen WH, Kline Leidy N. Development and first validation of the COPD Assessment Test. Eur Respir J. 2009;34(3):648-654.

20. Kusano M, Shimoyama Y, Sugimoto S, et al. Development and evaluation of FSSG: frequency scale for the symptoms of GERD. J Gastroenterol. 2004;39(9):888-891.

21. Ito K, Kawayama T, Shoji Y, et al. Depression, but not sleep disorder, is an independent factor affecting exacerbations and hospitalization in patients with chronic obstructive pulmonary disease. Respirology. 2012;17(6):940-949.

22. Suetomo M, Kawayama T, Kinoshita T, et al. COPD assessment tests scores are associated with exacerbations in Japanese patients with chronic obstructive pulmonary disease. Respir Investig. 2014;52(5):288-295.

23. Tashkin DP, Celli B, Senn S, et al. A 4-year trial of tiotropium in chronic obstructive pulmonary disease. N Engl J Med. 2008;359(15): 1543-1554.

24. Global Initiative for Asthma. Global Strategy for Asthma Management and Prevention. Bethesda (MD): GINA; 2015.

25. Soler-Cataluña JJ, Cosío B, Izquierdo JL, et al. Consensus document on the overlap phenotype COPD-asthma in COPD. Arch Bronconeumol. 2012;48(9):331-337.

26. Divo M, Cote C, de Torres JP, et al. Comorbidities and risk of mortality in patients with chronic obstructive pulmonary disease. Am J Respir Crit Care Med. 2012;186(2):155-161.

27. Charlson ME, Pompei P, Ales KL, MacKenzie CR. A new method of classifying prognostic comorbidity in longitudinal studies: development and validation. J Chronic Dis. 1987;40(5):373-383.

28. Japan Diabetes Society. Evidence-based practice guideline for the treatment of diabetes in Japan 2013. 2014. Available from: http://www.jds. or.jp/modules/en/index.php?content_id=44. Accessed December 23, 2015.

29. Rodriguez-Roisin R. Toward a consensus definition for COPD exacerbations. Chest. 2000;117(5 Suppl 2):398S-401S.
30. Calverley PM, Anderson JA, Celli B, et al. Salmeterol and fluticasone propionate and survival in chronic obstructive pulmonary disease. N Engl J Med. 2007;356(8):775-789.

31. Kessler R, Faller M, Fourgaut G, Mennecier B, Weitzenblum E. Predictive factors of hospitalization for acute exacerbation in a series of 64 patients with chronic obstructive pulmonary disease. Am J Respir Crit Care Med. 1999;159(1):158-164.

32. McGarvey L, Lee AJ, Roberts J, Gruffydd-Jones K, McKnight E, Haughney J. Characterisation of the frequent exacerbator phenotype in COPD patients in a large UK primary care population. Respir Med. 2015;109(2):228-237.

33. Balcells E, Antó JM, Gea J, et al. Characteristics of patients admitted for the first time for COPD exacerbation. Respir Med. 2009;103(9): 1293-1302.

34. Donaldson GC, Müllerova H, Locantore N, et al. Factors associated with change in exacerbation frequency in COPD. Respir Res. 2013;14:79.

35. Xu W, Collet JP, Shapiro S, et al. Negative impacts of unreported COPD exacerbations on health-related quality of life at 1 year. Eur Respir J. 2010;35(5):1022-1030.

36. Langsetmo L, Platt RW, Ernst P, Bourbeau J. Underreporting exacerbation of chronic obstructive pulmonary disease in a longitudinal cohort. Am J Respir Crit Care Med. 2008;177(4):396-401.

37. Wise RA, Anzueto A, Cotton D, et al. Tiotropium Respimat inhaler and the risk of death in COPD. N Engl J Med. 2013;369(16):1491-1501.

38. Tanabe N, Muro S, Hirai T, et al. Impact of exacerbations on emphysema progression in chronic obstructive pulmonary disease. Am J Respir Crit Care Med. 2011;183(12):1653-1659.

39. Atlantis E, Fahey P, Cochrane B, Smith S. Bidirectional associations between clinically relevant depression or anxiety and COPD: a systematic review and meta-analysis. Chest. 2013;144(3):766-777.

40. Menezes AM, Montes de Oca M, Pérez-Padilla R, et al. Increased risk of exacerbation and hospitalization in subjects with an overlap phenotype: COPD-asthma. Chest. 2014;145(2):297-304.

41. Fisher KA, Stefan MS, Darling C, Lessard D, Goldberg RJ. Impact of COPD on the mortality and treatment of patients hospitalized with acute decompensated heart failure: the Worcester Heart Failure Study. Chest. 2015;147(3):637-645.

42. Terada K, Muro S, Sato S, et al. Impact of gastro-oesophageal reflux disease symptoms on COPD exacerbation. Thorax. 2008;63(11): 951-955.

43. Japanese Respiratory Society. [Guidelines for the diagnosis and treatment of COPD (chronic obstructive pulmonary disease)]. 3rd ed. Tokyo: Medical Review Co; 2009. Japanese.

44. Crim C, Dransfield MT, Bourbeau J, et al. Pneumonia risk with inhaled fluticasone furoate and vilanterol compared with vilanterol alone in patients with COPD. Ann Am Thorac Soc. 2015;12(1):27-34.

45. DiSantostefano RL, Sampson T, Le HV, Hinds D, Davis KJ, Bakerly ND. Risk of pneumonia with inhaled corticosteroid versus long-acting bronchodilator regimens in chronic obstructive pulmonary disease: a new-user cohort study. PLoS One. 2014;9(5):e97149.

46. Kew KM, Seniukovich A. Inhaled steroids and risk of pneumonia for chronic obstructive pulmonary disease. Cochrane Database Syst Rev. 2014;3:CD010115.
International Journal of COPD

\section{Publish your work in this journal}

The International Journal of COPD is an international, peer-reviewed journal of therapeutics and pharmacology focusing on concise rapid reporting of clinical studies and reviews in COPD. Special focus is given to the pathophysiological processes underlying the disease, intervention programs, patient focused education, and self management protocols.
Dovepress

This journal is indexed on PubMed Central, MedLine and CAS. The manuscript management system is completely online and includes a very quick and fair peer-review system, which is all easy to use. Visit http://www.dovepress.com/testimonials.php to read real quotes from published authors. 